\title{
Correção do efeito ambiental em ensaios de famílias de soja, intercaladas com testemunhas, para predição de ganhos por seleção ${ }^{1}$
}

\author{
Correction of the environmental effect on evaluation of soybean families inserted \\ with controls, for prediction of selection gain
}

\author{
Rogério Luiz Backes ${ }^{2}$ Múcio Silva Reis ${ }^{3}$ Cosme Damião Cruz \\ Tuneo Sediyama ${ }^{3}$ Rita de Cássia Teixeira ${ }^{5}$
}

\section{RESUMO}

\begin{abstract}
Avaliou-se uma população $F_{5}$ de soja, em Viçosa$M G$, no ano agrícola 1997/98. O esquema experimental utilizado foi de famílias sem repetições, intercaladas com testemunhas, com repetições, possibilitando a estimação do componente ambiental associado à variância fenotípica da população em estudo e, conseqüentemente, os parâmetros genéticos. As avaliações de famílias e de individuos dentro de família permitiram decompor a variância genotipica e estimar a herdabilidade no sentido restrito. Com base nas repetições das testemunhas procedeu-se a correção do efeito ambiental. A correção do efeito ambiental favoreceu a seleção de famílias que originalmente apresentaram desempenho pouco inferior ao ponto de corte original, mas que foram desfavorecidas pelo ambiente, provocando assim alterações no grupo de famílias selecionadas através da simulação da mesma estratégia de seleção sobre os dados originais e corrigidos.
\end{abstract}

Palavras-chave: Glycine max, melhoramento genético, correção do efeito ambiental.

\section{ABSTRACT}

One $F_{5}$ soybean population was evaluated in Viçosa-MG, Brazil, during the 1997/98 growing season. The experimental design was of families without replications, inserted with controls, with replications, allowing the estimation of the environmental component associated to the phenotypic variance of the population under study, and consequently the genetic parameters. The evaluations at family and at individual within the family allowed to decompose the genotypic variance and to estimate the heritability on the narrow sense. The environmental effect correction was based on the replications of controls. The correction of the environment effect favored the selection of the families that originally showed performance a little inferior to the original selection truncation point, but were not favorable by the environmental, causing changes in the family groups selected through the simulation of the same selection strategies on the original and corrected data.

Key words: Glycine max, breeding, correction of the environmental effect.

\section{INTRODUÇÃO}

Os delineamentos experimentais obedecem a três princípios básicos: repetição, casualização e controle local, e é da observação destes princípios que depende a maior ou menor validez das conclusões obtidas. O ideal é utilizar grande número de repetições, buscando maior precisão experimental, pela diminuição dos efeitos ambientais. A casualização tem por finalidade evitar que as repetições de um determinado tratamento venham a ser continuamente favorecidas ou desfavorecidas pelo ambiente, quando distribuídas nas diversas unidades experimentais, enquanto, o controle

${ }^{1}$ Parte da dissertação de mestrado apresentada pelo primeiro autor à Universidade Federal de Viçosa (UFV).

${ }^{2}$ Engenheiro Agrônomo, Doutorando em Genética e Melhoramento da UFV (Bolsista do CNPq). 36571-000 - Viçosa, MG.

E-mail: rogerio@backes.com.br. Autor para correspondência.

${ }^{3}$ Engenheiro Agrônomo, Doutor, Professor Titular do Departamento de Fitotecnia, UFV. Bolsista do CNPq.

${ }^{4}$ Engenheiro Agrônomo, Doutor, Professor Titular do Departamento de Biologia Geral, UFV. Bolsista do CNPq.

${ }^{5}$ Economista Doméstica, Mestre, Bolsista do Programa de Melhoramento Genético da Soja do Dept. de Fitotecnia da UFV. 
local deve ser exercido através da utilização de áreas mais homogêneas ou pela divisão da área em blocos. A observação destes princípios garante validade às inferências estatísticas, dando confiabilidade à comparação de médias no processo de seleção (GOMES, 1990; RAMALHO et al., 2000).

Porém, na avaliação de gerações segregantes em programas de melhoramento de plantas, a exemplo da soja, pelo menos três fatores limitam a utilização de repetições: a pequena quantidade de sementes disponíveis; o grande número de materiais a serem avaliados e a falta de homogeneidade genética nas primeiras gerações de autofecundação, mesmo entre sementes oriundas de uma única planta. Assim, não se pode considerar como repetições parcelas entre as quais, além das diferenças ambientais, exista heterogeneidade genética. Mesmo na avaliação de linhagens e clones, muitas vezes o que dificulta a utilização de delineamentos experimentais é o grande número de tratamentos a serem avaliados.

Uma alternativa para contornar estas dificuldades é a utilização de blocos aumentados (FEDERER, 1956). Neste delineamento, são considerados dois tipos de tratamentos: os tratamentos comuns a todos os blocos, ou seja, as testemunhas, e o segundo tipo, os tratamentos regulares, que aparecem em apenas um dos blocos, ou seja, sem repetições. Neste delineamento, as observações dos tratamentos regulares de cada bloco são corrigidas em função da diferença entre a média geral das testemunhas e a média das testemunhas naquele bloco. Desta forma, todos os tratamentos regulares de um mesmo bloco são ajustados por um único índice, obtido com base nas testemunhas.

O objetivo deste trabalho foi apresentar uma alternativa para a avaliação de grande número de famílias, utilizando apenas repetições de testemunhas, e propor um método para a correção do efeito ambiental para fins de estimação dos parâmetros genéticos e predição de ganhos por seleção.

\section{MATERIAL E MÉTODOS}

Este trabalho foi conduzido como parte do programa de melhoramento de soja do Departamento de Fitotecnia da Universidade Federal de Viçosa, no ano agrícola 1997/98. A população estudada foi composta por 81 famílias $\mathrm{F}_{5}$, oriundas do cruzamento de 'Agratech 550' com 'FT - Cristalina RC4F 4 '. Estes genótipos são divergentes quanto à região de adaptação, além de outras características, sendo o cultivar Agratech 550 não adaptado a esta região. $\mathrm{O}$ outro genitor foi obtido por quatro gerações de retrocruzamento (RC4) para a incorporação de resistência a cancro da haste em 'FT - Cristalina', sendo então o 'FT - Cristalina RC4' autofecundado por quatro gerações $\left(\mathrm{F}_{4}\right)$. O experimento foi instalado em 05/12/97, na Universidade Federal de Viçosa, MG $\left(650 \mathrm{~m}, 20^{\circ} 45^{\prime} \mathrm{S}, 42^{\circ} 51^{\prime} \mathrm{W}\right)$. O preparo do solo consistiu de uma aração seguida de duas gradagens, a adubação foi realizada no sulco de plantio, aplicandose $70 \mathrm{~kg} / \mathrm{ha} \mathrm{de} \mathrm{P}_{2} \mathrm{O}_{5}$ e $35 \mathrm{~kg} /$ ha de $\mathrm{K}_{2} \mathrm{O}$. Foram realizadas pulverizações, para controle de pragas, e irrigações, conforme a necessidade da cultura.

A distribuição do material experimental no campo foi de famílias intercaladas com testemunhas. Este sistema é, na verdade, uma derivação do delineamento de blocos aumentados (FEDERER, 1956), em que as testemunhas equivalem aos tratamentos comuns, e as famílias, aos tratamentos regulares. Neste experimento, os próprios parentais foram utilizados como testemunhas. O esquema experimental pode ser assim descrito: a $1^{\text {a }}$ parcela foi composta pela testemunha ( $1^{\mathrm{a}}$ repetição do genitor 1$)$; nas próximas cinco parcelas $\left(2^{\mathrm{a}} \mathrm{a} 6^{\mathrm{a}}\right)$, foram semeadas progênies de cada planta selecionada da população em estudo. A parcela seguinte $\left(7^{\mathrm{a}}\right)$ foi ocupada pela outra testemunha (1 ${ }^{a}$ repetição do genitor 2 ); na seqüência, mais cinco parcelas foram ocupadas com famílias ( $8^{\mathrm{a}}$ a $\left.12^{\mathrm{a}}\right)$; e novamente, repetiu-se uma parcela (13 ${ }^{\mathrm{a}}$ ) com a primeira testemunha (2 $2^{\mathrm{a}}$ repetição do genitor 1), e assim sucessivamente, até terminar todas as famílias. A parcela foi constituída de uma fileira de $1,0 \mathrm{~m}$, no espaçamento de $0,70 \mathrm{~m}$ entre fileiras. Foram utilizadas 30 sementes por parcela na semeadura, e de 15 a 20 dias após a emergência foi feito o desbaste, para 15 plantas $\mathrm{m}^{-1}$. Para a avaliação, foram etiquetadas seis plantas competitivas dentro de cada parcela.

Os seguintes caracteres foram avaliados: número de dias para florescimento (DPF); altura da planta no florescimento, em centímetros (APF); número de nós no florescimento (NNF); número de dias para maturação, estádio R8 (DPM); altura da planta na maturação (APM); número de nós na maturação (NNM); número de vagens por planta (NVP); produção de grãos de cada planta, em gramas (PRO).

A análise de variância foi realizada, considerando o seguinte modelo estatístico, conforme apresentado por CRUZ (2001) e BACKES et al. (2002): $Y_{i j}=\mu+f_{i}+e_{i}+d_{i j}+\delta_{i j}$, em que: $\mu=$ média geral (testemunhas ou famílias); $f_{i}=$ efeito genético atribuído à i-ésima família (inexistente para as testemunhas); $e_{i}=$ efeito ambiental entre fileiras (de uma testemunha ou de famílias); $d_{i j}=$ efeito genético atribuído à j-ésima planta da i-ésima família (inexistente para as testemunhas); e $\delta_{i j}=$ efeito ambiental entre plantas 
dentro da fileira (de uma testemunha ou de famílias).

$\mathrm{O}$ estimador da variância fenotípica entre famílias $\left(\hat{\sigma}_{F b}^{2}\right)$ foi o QMEf, e o estimador da variância fenotípica dentro de famílias $\left(\hat{\sigma}_{F w}^{2}\right)$ foi o QMDf (Tabela 1). A variância ambiental foi estimada com base na variação fenotípica entre as repetições das testemunhas (genitores) intercaladas entre as famílias. Assim, a variância ambiental entre $\left(\hat{\sigma}_{E w}^{2}\right)$ e dentro $\left(\hat{\sigma}_{F b}^{2}\right)$ de famílias foi estimada, respectivamente, por

$$
\begin{aligned}
& \hat{\sigma}_{E b}^{2}=\frac{\left(r_{1}-1\right) Q M E p 1+\left(r_{2}-1\right) Q M E p 2}{r_{1}+r_{2}-2} \mathrm{e} \\
& \hat{\sigma}_{E w}^{2}=\frac{\left(r_{1} p-r_{1}\right) Q M D p 1+\left(r_{2} p-r_{2}\right) Q M D p 2}{p\left(r_{1}+r_{2}\right)-r_{1}-r_{2}}
\end{aligned}
$$

Por diferença, conforme RAMALHO e VENCOVSKY (1978), obteve-se a variância genotípica entre $\left(\hat{\sigma}_{G b}^{2}\right)$ e dentro $\left(\hat{\sigma}_{G w}^{2}\right)$ de famílias, respectivamente por: $\hat{\sigma}_{G b}^{2}=\hat{\sigma}_{F b}^{2}-\hat{\sigma}_{E b}^{2}$ e $\hat{\sigma}_{G w}^{2}=\hat{\sigma}_{F w}^{2}-\hat{\sigma}_{E w}^{2}$. As variâncias genotípicas foram decompostas em variância aditiva $\left(\hat{\sigma}_{A}^{2}\right)$ e devida à dominância $\left(\hat{\sigma}_{D}^{2}\right)$, por meio das expressões de distribuição desta entre e dentro de famílias autofecundadas, citadas por FALCONER(1987):

$$
\begin{aligned}
& \hat{\sigma}_{G b}^{2}=2 F_{n} \hat{\sigma}_{A}^{2}+F_{n}\left(1-F_{n}\right) \hat{\sigma}_{D}^{2} \\
& \hat{\sigma}_{G w}^{2}=\left(1-F_{n}\right) \hat{\sigma}_{A}^{2}+\left(1-F_{n}\right) \hat{\sigma}_{D}^{2},
\end{aligned}
$$

considerando o coeficiente de endogamia $\left(F_{n}\right)$ da geração $\mathrm{F}_{5}$ igual a $7 / 8$, conforme RAMALHO e VENCOVSKY (1978). O coeficiente de herdabilidade no sentido restrito $\left(h^{2}\right)$, para média de famílias, foi estimado por $h^{2}=\left(2 F_{n} \hat{\sigma}_{A}^{2} / \hat{\sigma}_{F b}^{2}\right)$. Optou-se por estimar a herdabilidade no sentido restrito, pois esta reflete a fração explorável pela seleção, por considerar apenas a variância de natureza aditiva, desprezando a fração da variância genética devida à dominância.
A condução de testemunhas intercaladas, conseqüentemente com repetições, permitiu obter estimativas do efeito ambiental e com este corrigir as diferenças entre famílias que tinham como causa diferenças ambientais. Assim, o efeito ambiental foi estimado a partir do desvio das repetições de testemunhas em relação à média geral das mesmas no experimento. Desta forma, quando o desempenho das repetições de testemunhas em um determinado ponto estiver acima da média, diz-se que o ambiente adjacente a este é favorável, e as famílias localizadas na área adjacente foram beneficiadas pelo ambiente. Ao contrário, quando o desempenho de determinadas repetições da testemunha for inferior à média, o ambiente neste local foi desfavorável e prejudicou o desempenho das famílias próximas. Como as testemunhas respondem de forma diferenciada às diferenças de condições ambientais, utilizou-se a média destas para a correção do efeito ambiental. Assim, primeiramente obteve-se a média entre as repetições equivalentes das testemunhas 1 e 2 , que se encontravam em seqüência no campo, e calculou-se a posição média entre as duas testemunhas consecutivas através da média da numeração das parcelas, ou seja: $\bar{X}_{l}=\frac{\bar{Y}_{1 . k}+\bar{Y}_{2 . k}}{2}$ e $l=\frac{l_{1 k}+l_{2 k}}{2}$, em que: $\overline{X_{i}}$ é a média na posição $l ; \bar{Y}_{1 . k}$ e $\bar{Y}_{2 . k}$ são as médias das testemunhas 1 e 2 , respectivamente, na repetição $k$; $l$ é o número da parcela da posição média (ponto médio), localizada entre as testemunhas $1 \mathrm{e} 2$, da repetição $k ; l_{1 k}$ e $l_{2 k}$ são os números das parcelas ocupadas pela repetição $k$ das testemunhas 1 e 2 , respectivamente.

O efeito ambiental é o desvio de cada ponto médio em relação a média geral das testemunhas, ou seja: $E A_{l}=\bar{X}_{l}-\mu$, em que: $E A_{l}$ é o efeito ambiental na posição $l ; \mu$ é a média geral das testemunhas. Os

Tabela 1 - Esquema da análise de variância.

\begin{tabular}{cllllll}
\hline \multirow{2}{*}{ FV } & \multicolumn{2}{c}{ Famílias } & & \multicolumn{2}{c}{ Testemunha 1 (Genitor 1) } & \multicolumn{2}{c}{ Testemunha 2 (Genitor 2) } \\
\cline { 2 - 7 } & $\mathrm{GL}^{1 /}$ & $\mathrm{QM}^{3 /}$ & $\mathrm{GL}^{2 /}$ & $\mathrm{QM}^{3 /}$ & $\mathrm{GL}^{2 /}$ & $\mathrm{QM}^{3 /}$ \\
\hline Entre parcelas & $f-1$ & $Q M E f$ & $r_{1}-1$ & $Q M E p 1$ & $r_{2}-1$ & $Q M E p 2$ \\
Dentro de parcelas & $f n-f$ & $Q M D f$ & $r_{1} p-r_{1}$ & $Q M D p 1$ & $r_{2} p-r_{2}$ & $Q M D p 2$ \\
Total & $f n-1$ & & $r_{1} p-1$ & & $r_{2} p-1$ & \\
\hline
\end{tabular}

${ }^{1 /} f=$ número de famílias em avaliação; e $\mathrm{n}=$ número de plantas por família.

${ }^{2 /} r_{1}$ e $r_{2}=$ número de repetições da testemunha 1 e 2 , respectivamente; e $\mathrm{p}=$ número de plantas por repetição da testemunha.

${ }^{3 /} Q M E=$ quadrado médio entre famílias ou entre repetições de testemunha; e $Q M D=$ quadrado médio entre plantas dentro das famílias ou entre plantas dentro das repetições da testemunha. 
valores corrigidos foram obtidos subtraindo-se do valor observado a campo o efeito ambiental, de modo a anular as diferenças entre famílias que são devidas à localização. A correção foi feita em gradiente, com base em dois efeitos ambientais seqüenciais, de modo a obter uma correção gradual, de acordo com a distância entre parcela a ser corrigida e os dois efeitos ambientais estimados nos pontos médios, um antecede, e o outro é subseqüente à família a ser corrigida. A correção foi realizada com base na seguinte equação: $Y_{c}=Y_{o}-E A_{l}+\frac{q}{t+1}\left(E A_{l}-E A_{l+t}\right) \mathrm{em}$ que: $Y_{C}$ e $Y_{O}$ é o valor corrigido e o valor observado, respectivamente; $q$ é a posição em relação ao ponto médio $l$ (número de parcelas do ponto médio que antecede a família até esta); $t$ é o número total de parcelas entre os dois pontos médios; $E A_{l}$ e $E A_{l+t}$ são os efeitos ambientais, antecedente e subseqüente à família a ser corrigida, respectivamente.

Assim, para $q=0$, tem-se: $Y_{c}=Y_{o}-E A_{l}$ e para $q=t+1$, tem-se: $Y_{c}+Y_{0}-E A_{l+t}$, ressalta-se que os pontos $q=0$ e $q=t+1$ correspondem a parcelas de testemunhas entre o grupo de $f$ famílias avaliadas. As duas primeiras parcelas do experimento antecediam o primeiro ponto médio. Assim, foram corrigidas com o efeito ambiental estimado para este ponto, devido à impossibilidade da obtenção de um gradiente para as mesmas.

Após a correção dos dados, foi estimada a herdabilidade corrigida, utilizando para tanto a variância genética já estimada e uma nova variância fenotípica entre famílias, estimada com base nos valores corrigidos. Na seqüência, foram simuladas três estratégias de seleção, nos dados originais e nos dados corrigidos: 1) seleção sobre o NVP; 2) seleção sobre a PRO e 3) seleção sobre o índice de PESEK \& BAKER (1969). O índice de Pesek e Baker, também conhecido como índice com base nos ganhos desejados, dispensa o estabelecimento prévio de pesos econômicos para os caracteres, sendo necessário apenas estabelecer ganhos desejados para os diferentes caracteres. A utilização do índice de Pesek e Baker tem mostrado resultados satisfatórios quando da utilização de ganhos desejados correspondentes a um desvio padrão genético (CRUZ \& REGAZZI, 1997). Os coeficientes de ponderação $(\hat{b})$ foram estimados por: $\hat{b}=G^{-1} \Delta g_{d}$, considerando simultaneamente os caracteres APM, DPM e PRO, e ganhos desejados $\left(\Delta g_{d}\right)$ iguais a um desvio padrão genético para cada caráter. Para os caracteres APM e DPM, consideraram-se ganhos desejados de sinal negativo, pois pretendia-se selecionar famílias de porte baixo e mais precoces. $\mathrm{O}$ símbolo $G$ representa a matriz de covariâncias genéticas entre os caracteres considerados. O índice foi estimado por: $I_{p b}=\hat{b}^{\prime} x$, em que $x$ é a matriz de valores dos caracteres.

A resposta direta a seleção $(G S)$ foi estimada por: $G S=D S^{*} h^{2}$, onde $D S$ é o diferencial de seleção. Os ganhos indiretos da seleção foram estimados conforme sugerido por CRUZ e REGAZZI (1997): $G S_{x(y)}=D S_{x(y)}{ }^{*} h^{2}(x)$, em que $G S_{x(y)}$ é a resposta em $X$, quando a seleção é praticada em $Y$; $D S_{x(y)}$ é o diferencial de seleção do caráter $X$, quando da seleção com base no caráter $Y$; e $h^{2}{ }_{(x)}$ é a herdabilidade restrita do caráter $X$. As análises estatísticas foram processadas no programa GENES (CRUZ, 2001).

\section{RESULTADOS E DISCUSSÃO}

As repetições das testemunhas intercaladas na população serviram para a estimação do componente ambiental associado à variância fenotípica, permitindo a estimação de parâmetros genéticos, conforme apresentado por CRUZ (2001) e BACKES et al. (2002). Simultaneamente, as testemunhas intercaladas possibilitaram a estimação dos efeitos ambientais, através dos desvios das repetições em relação à média geral. As duas testemunhas respondem de forma diferenciada ao ambiente, sendo que os desvios de cada repetição em relação à média do respectivo cultivar são muito distintos entre as testemunhas. Ou seja, os efeitos ambientais que poderiam ser estimados com base no 'Agratech 550' serão de magnitude muito inferior aos obtidos com base no 'FT-Cristalina RC4', conforme pode ser observado para o NVP na Figura 1a. Este comportamento diferencial ocorre em maior ou menor intensidade em todos os caracteres avaliados, sendo que o genitor mais adaptado, além da média superior, apresenta maiores oscilações no desempenho, respondendo de maneira mais intensa às variações ambientais existentes entre as repetições. Estes resultados concordam com FALCONER (1987), quando afirma que diferentes genótipos certamente promoverão estimativas distintas de variância ambiental, por serem mais ou menos sensíveis à influência do ambiente.

Portanto, um procedimento mais adequado seria intercalar pares de genitores às famílias, em vez de intercalar alternadamente uma e outra testemunha, ou ainda, optar por uma testemunha adaptada, estável e de bom desempenho na região, dispensando assim a estimação dos pontos médios, para posterior correção do efeito ambiental. A utilização dos próprios parentais como testemunhas deverá ser vantajosa, pois os efeitos 


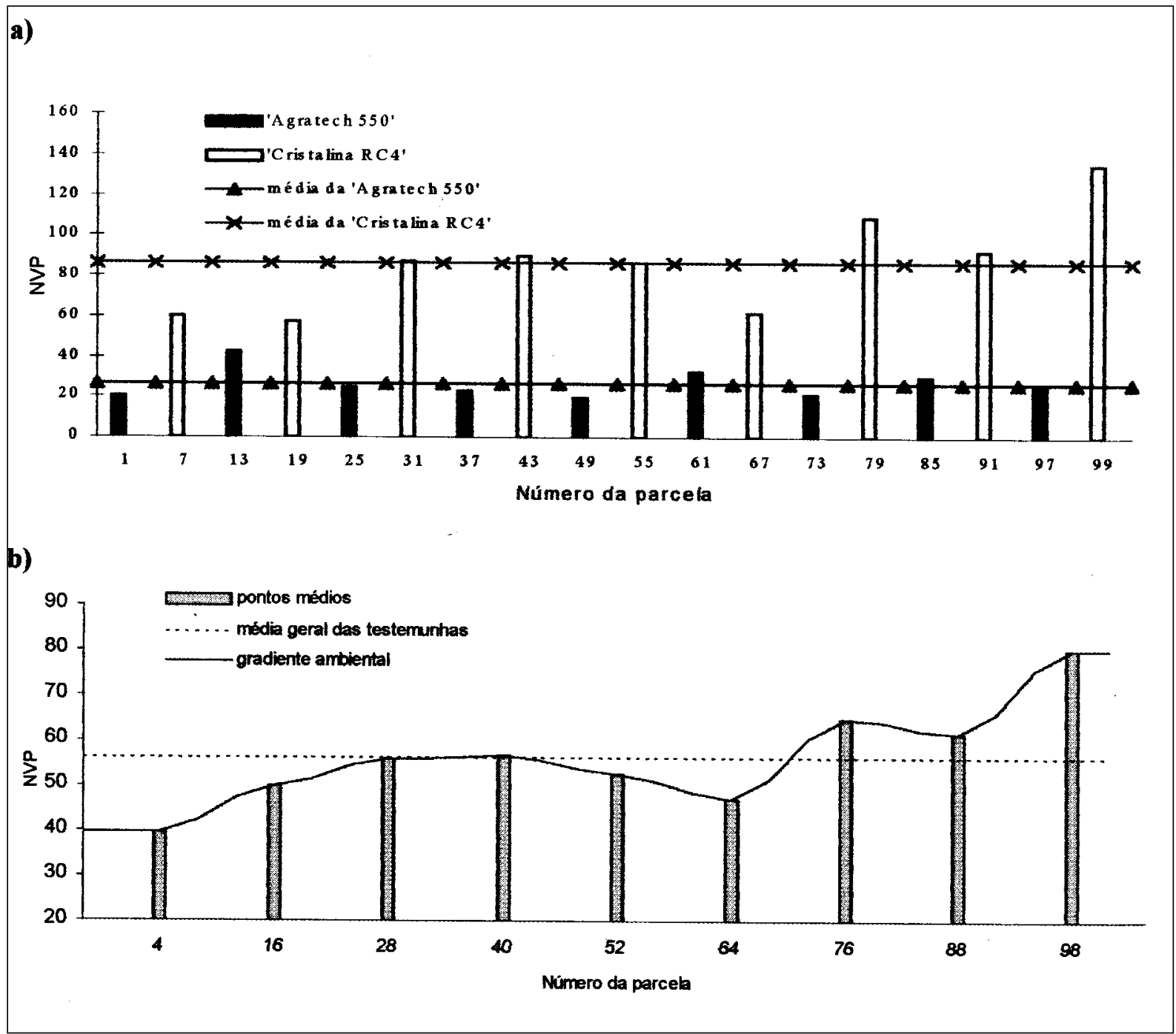

Figura 1 - a) Número de vagens por planta (NVP), de ‘Agratech 550' e 'FT-Cristalina RC4' nas parcelas intercalares (repetições), e média de NVP de cada uma das cultivares (testemunhas) no experimento. b) NVP estimado para os pontos médios entre pares de testemunhas, média geral das testemunhas no experimento e gradiente ambiental.Viçosa - MG. Ano agrícola 1997/98.

ambientais serão estimados com o mesmo conjunto de genes que constituem as populações, na expectativa de que as respostas ao ambiente sejam mais similares. Para evitar a correção diferencial, em função de qual dos progenitores (testemunhas) está estimando o efeito ambiental, utilizou-se para tanto, a média entre as duas testemunhas. Primeiramente, obtendo-se um ponto médio, localizado entre duas testemunhas de mesma repetição, e uma estimativa de desempenho para este ponto (Figura 1b). Assim, o efeito ambiental é o desvio do gradiente ambiental obtido através dos pontos médios em relação à média geral das testemunhas. Quando a linha que indica o gradiente ambiental está abaixo da média geral, o ambiente é considerado desfavorável, e a diferença entre estas será adicionada ao desempenho das famílias aí localizadas. No entanto, onde a linha do gradiente ambiental indica ambientes superiores à média geral, a diferença entre estas será subtraída no desempenho das famílias localizadas nesta área.

Com a avaliação de famílias sem repetições, há uma clara tendência das variações ambientais favorecerem algumas famílias, suprimindo as diferenças genéticas existentes entre as famílias, dificultando a seleção entre essas unidades. Portanto, o objetivo básico de se proceder a correção dos dados é eliminar as diferenças puramente ambientais entre os

Ciência Rural, v. 33, n. 6, nov-dez, 2003. 
candidatos à seleção, de forma que os valores corrigidos deverão demonstrar melhor as diferenças genéticas entre as unidades.

As estimativas da herdabilidade no sentido restrito entre famílias, para os valores originais e corrigidos do efeito ambiental, são apresentadas na tabela 2. Vale lembrar que a herdabilidade para dados corrigidos é estimada com base na variância aditiva estimada nos dados originais e com a variância fenotípica entre os dados corrigidos. Para os caracteres DPF, APF, NNF, APM e NNM as herdabilidades aumentaram após a correção dos dados, demonstrando a eficiência desta na diminuição da variância fenotípica. Nos casos em que a herdabilidade aumentou, o valor fenotípico, após a correção passa a ser um melhor indicador do valor genético da família, do que o valor de antes da correção. Porém, nos caracteres DPM, NVP e PRO as herdabilidades diminuíram após a correção, em função do aumento da variância fenotípica, sendo esta redução mais intensa no caráter DPM. O motivo desta redução, por exemplo, no caráter NVP pode ser compreendido a partir da figura 2 que apresenta graficamente o NVP das famílias antes e após a correção do efeito ambiental. Observa-se que, entre a parcela 2 e a 62 (Figura 2), apesar do ambiente ser desfavorável (Figura 1b), há famílias com desempenho superior à média $(65,68)$, apresentada na tabela 2 , e após a correção do efeito ambiental, esta superioridade aumentou, incrementando os desvios em relação à média corrigida $(66,88)$ e, conseqüentemente, a variância fenotípica. Por outro lado, entre as parcelas 71 e 98 (Figura 2), mesmo em ambiente favorável (Figura 1b), algumas famílias tiveram desempenho inferior à média, e com a correção esta diferença ficou mais acentuada, aumentando a magnitude dos desvios em relação à média, também colaborando para o aumento da variância fenotípica. Destaca-se que, apesar da soma dos fatores de correção ser igual a zero, a média corrigida não foi igual à média original, pois o número de famílias corrigidas com base em cada um dos pontos médios

Tabela 2 - Herdabilidades no sentido restrito entre famílias, média da população e estimativas de ganhos percentuais diretos e indiretos com a simulação de três estratégias de seleção, sobre os dados originais (Ori) e corrigidos do efeito ambiental (Cor), número de famílias simultaneamente selecionadas com a simulação da mesma estratégia sobre dados originais e corrigidos. Viçosa - MG. Ano agrícola 1997/98.

\begin{tabular}{|c|c|c|c|c|c|c|}
\hline \multirow{2}{*}{ Caráter } & \multirow{2}{*}{ Dados } & \multirow{2}{*}{$\begin{array}{l}\text { Herdabilidade } \\
\text { restrita }\end{array}$} & \multirow{2}{*}{ Média da população } & \multicolumn{3}{|c|}{ Estratégia de seleção $^{1 /}$} \\
\hline & & & & S-NVP & S-PRO & S-IPB \\
\hline \multirow[t]{2}{*}{ DPF } & Ori & 96,27 & 57,88 & 7,83 & 1,61 & $-6,07$ \\
\hline & Cor & 113,47 & 57,88 & 7,43 & 1,16 & $-15,05$ \\
\hline \multirow[t]{2}{*}{ APF } & Ori & 89,49 & 70,57 & 13,59 & 4,49 & $-6,50$ \\
\hline & Cor & 107,53 & 70,87 & 13,08 & 6,31 & $-20,24$ \\
\hline \multirow[t]{2}{*}{ NNF } & Ori & 87,81 & 13,71 & 9,26 & 3,46 & $-4,01$ \\
\hline & Cor & 102,44 & 13,75 & 11,21 & 4,88 & $-12,87$ \\
\hline \multirow[t]{2}{*}{ DPM } & Ori & 50,67 & 136,41 & 1,57 & 0,68 & $-2,35$ \\
\hline & Cor & 35,93 & 136,45 & 0,65 & $-0,13$ & $-2,78$ \\
\hline \multirow[t]{2}{*}{ APM } & Ori & 81,00 & 91,90 & 11,58 & 3,98 & $-7,01$ \\
\hline & Cor & 105,15 & 92,54 & 8,46 & 2,27 & $-24,00$ \\
\hline \multirow[t]{2}{*}{ NNM } & Ori & 75,55 & 16,69 & 7,58 & 2,82 & $-4,77$ \\
\hline & Cor & 96,79 & 16,81 & 6,84 & 0,91 & $-15,41$ \\
\hline \multirow[t]{2}{*}{ NVP } & Ori & 19,10 & 65,68 & 6,41 & 4,69 & 1,31 \\
\hline & Cor & 18,84 & 66,88 & 6,57 & 5,10 & $-0,45$ \\
\hline \multirow[t]{2}{*}{ PRO } & Ori & 16,43 & 16,60 & 4,67 & 5,78 & 3,87 \\
\hline & Cor & 16,24 & 16,80 & 4,61 & 5,81 & 2,93 \\
\hline
\end{tabular}

\begin{tabular}{cc}
\hline Estratégias de seleção & $\begin{array}{c}\text { Número de famílias que foram simultaneamente selecionadas pelas simulação da mesma estratégia sobre os } \\
\text { dados originais e corrigidos do efeito ambiental }\end{array}$ \\
\hline S-NVP $_{\text {Ori }}$ e S-NVP & 12 \\
S-PRO $_{\text {Ori }}$ e S-PRO Cor & 13 \\
S-IPB & 12
\end{tabular}

${ }^{1 /}$ S-NVP = seleção sobre o número de vagens por planta; S-PRO = seleção sobre a produção de grãos e S-IPB = seleção sobre o índice de Pesek e Baker.

${ }^{2 /}$ Fixou-se o percentual de seleção em $20 \%$, ou seja, 16 famílias em cada simulação. 
não foi constante, especificamente, no primeiro e no último ponto médio.

Apesar de, em alguns casos, a herdabilidade indicar que a correlação do valor fenotípico com o valor genotípico diminuiu após a correção, isto não inviabiliza a correção dos dados, pois, como é demonstrado pela figura 2 , a correção eliminou diferenças entre as famílias, cuja causa foi a localização, em ambientes favoráveis ou desfavoráveis, uniformizando o componente ambiental que atua na determinação do valor fenotípico e tornando as médias comparáveis, independentemente de estarem localizadas em áreas favorecidas ou prejudicadas pelo ambiente.

Nesta população, simulou-se a seleção de 16 famílias em cada estratégia. Em todas as estratégias, houve alterações no grupo de famílias selecionadas com base nos dados originais e nos corrigidos do efeito ambiental, refletindo alteração no ranking das famílias. $\mathrm{Na}$ seleção direta sobre a PRO, foram selecionadas simultaneamente 13 famílias, em dados originais e corrigidos. Com a seleção sobre o NVP e sobre o índice de Pesek e Baker, 12 famílias foram simultaneamente selecionadas, com base em dados originais e nos dados corrigidos (Tabela 2). A figura 2 mostra a alteração de ranking provocada com a correção do efeito ambiental para o NVP, onde é possível identificar as famílias substituídas no grupo de famílias selecionadas com base no NVP após a correção. As famílias localizadas nas parcelas 84, 89, 96 e 98 selecionadas com base nos valores originais foram substituídas pelas famílias que ocupavam as parcelas 2, 3, 5 e 54, na seleção sobre os dados corrigidos. Ressalta-se que a figura 2 apresenta apenas as parcelas ocupadas com as famílias. As parcelas ocupadas pelas testemunhas foram omitidas.

Com a correção, selecionam-se famílias que originalmente apresentaram desempenho um pouco abaixo do ponto de corte, porém estavam localizadas em ambientes desfavoráveis. Por outro lado, descartam-se aquelas famílias que apresentaram resultados pouco acima do ponto de corte, mas que, estavam sendo privilegiadas pela condição ambiental. Quando dois candidatos à seleção apresentam desempenho muito semelhante, e um destes estiver em um ambiente menos favorável, certamente este que produziu bem, mesmo com a restrição ambiental, é o mais interessante para o melhoramento. Este indivíduo deve ter maior valor genotípico e, a princípio, maior adaptabilidade. Desta forma, a correção de dados justifica-se por possibilitar a distinção entre indivíduos superiores avaliados em condições heterogêneas, permitindo a distinção entre indivíduos de desempenho semelhante, em função da condição ambiental em que

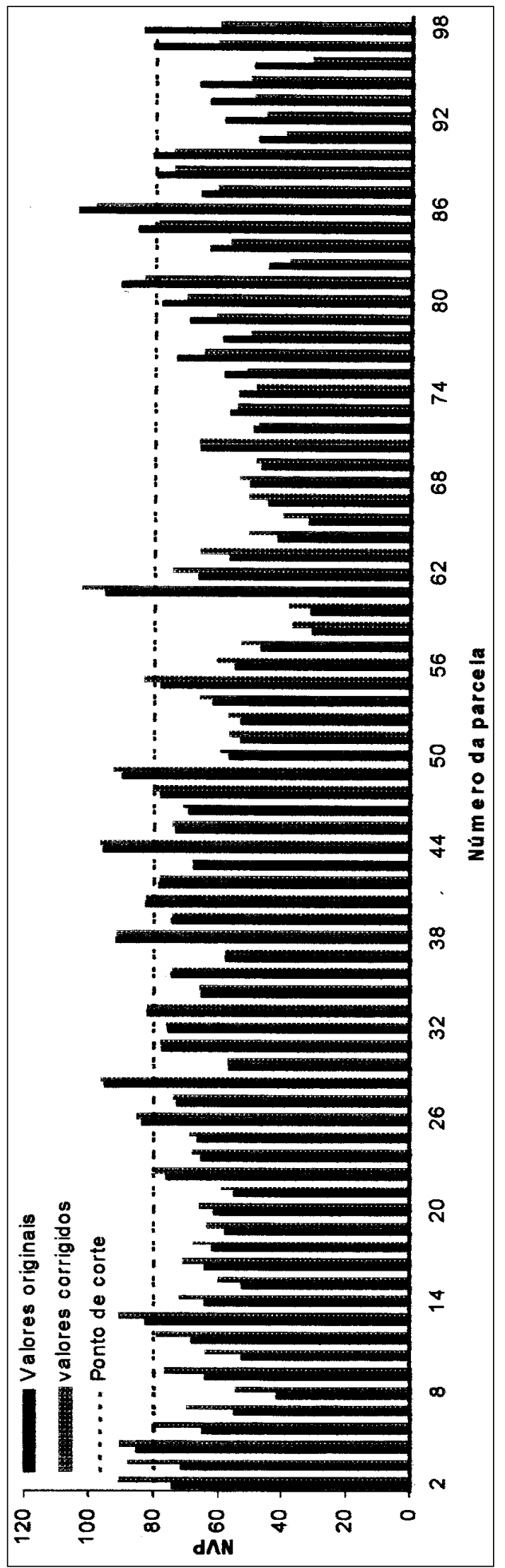

Ciência Rural, v. 33, n. 6, nov-dez, 2003. 
se desenvolveram, segundo os efeitos ambientais estimados pelas testemunhas.

\section{CONCLUSÕES}

A avaliação de famílias em ensaios sem repetições intercaladas com testemunhas repetidas mostrou-se uma alternativa viável para a estimação de parâmetros genéticos, que servirão de guia para a seleção. A correção dos efeitos ambientais auxilia na seleção entre famílias superiores que não estão sob condições ambientais totalmente homogêneas. Esta correção permite a seleção de famílias de desempenho inferior ao ponto de corte original, mas que foram desfavorecidas pelo ambiente, em detrimento a outras de desempenho um pouco superior, mas que estavam em ambientes mais favoráveis, segundo os efeitos ambientais estimados com base nas repetições das testemunhas.

\section{REFERÊNCIAS BIBLIOGRÁFICAS}

BACKES, R.L. et al. Estimativas de parâmetros genéticos em populações F5 e F6 de soja. Revista Ceres, Viçosa, v.49, n.282, p.201-216, 2002.
CRUZ, C.D.; REGAZZI, A.J. Modelos biométricos aplicados ao melhoramento genético. Viçosa : UFV, 1997. 390p.

CRUZ, C.D. Programa genes: versão Windows; aplicativo computacional em genética e estatística. Viçosa : UFV, 2001. 648p.

FALCONER, D.S. Introdução à genética quantitativa. Viçosa, MG : UFV, 1987. 279p.

FEDERER, W.T. Augmented (or hoonuiaku) designs. Hawaiian Planters Record, Honolulu, v.55, n.2, p.191$208,1956$.

GOMES, F.P. Curso de estatística experimental. 13. ed. Piracicaba : Nobel, 1990. 468p.

PESEK, J.; BAKER, R.J. Desired improvement in relation to selected indices. Canadian Journal Plant Science, v.49, p.803-804, 1969.

RAMALHO, M.A.P.; FERREIRA, D.F.; OLIVEIRA, A.C. Experimentação em genética e melhoramento de plantas. Lavras: UFLA, $2000.303 \mathrm{p}$.

RAMALHO, M.A.P.; VENCOVSKY, R. Estimação dos componentes da variância genética em plantas autógamas. Ciência e Prática, v.2, n.2, p.117-140, 1978. 